\title{
Estreitando relações entre Matemática, saúde e EJA com o auxílio da tecnologia
}

\author{
Paula Reis de Miranda \\ Mestre em Ensino de Ciências e Matemática pela PUC Minas \\ Doutoranda em Educação pela UFMG \\ Professora IF Sudeste MG - Campus Rio Pomba \\ paula.reis@ifsudestemg.edu.br
}

\section{Eliane Scheid Gazire}

Professora do Mestrado em Ensino de Ciências e Matemática - PUC Minas

egazire@terra.com.br

\begin{abstract}
Resumo
Diante da implantação do PROEJA na rede federal de Educação Profissional e Tecnológica, percebeu-se a necessidade de averiguar as possibilidades da construção de um material didático para ensino de Matemática para o curso de Agente Comunitário de Saúde, com o objetivo de oferecer ao estudante o desenvolvimento dos conhecimentos matemáticos de forma interdisciplinar, permitindo a formação integral do cidadão. A atividade aqui descrita foi aplicada com caráter exploratório-investigativo, sendo analisada e descrita com o objetivo de instrumentalizar o professor quanto às possibilidades de trabalho com a Matemática e a tecnologia no PROEJA, aproximando seus sujeitos das potencialidades da ferramenta tecnológica Geogebra.
\end{abstract}

Palavras-chave: PROEJA, Matemática, Saúde, Tecnologia, Material Didático.

\section{Strengthening relations between mathematics, health and EJA with the aid of technology}

\begin{abstract}
Before the deployment of the network PROEJA federal Vocational and Technological Education, it was realized the need to assess the possibilities of constructing a didactical material for mathematics teaching for the course of Community Health Agents, aiming to offer the student the development of mathematical knowledge in an interdisciplinary way, allowing the education of the citizen. The activity described here was applied with exploratory-investigative way, and it was analyzed and described in order to equip the teacher about the possibilities of working with mathematics and technology in PROEJA, approaching his subject from the potential of the technological tool Geogebra.
\end{abstract}

Keywords: PROEJA, Mathematics, Health, Technology, Teaching Materials. 


\section{Conhecendo a modalidade PROEJA}

A Educação de Jovens e Adultos (EJA) foi inserida com obrigatoriedade nas instituições federais de Educação Profissional e Tecnológica (EPT) por meio da Portaria 2.080/05 (BRASIL, 2005a), que determina a obrigatoriedade de oferta de $10 \%$ das vagas de ingresso para cursos técnicos integrados ao Ensino Médio na modalidade EJA a partir do ano de 2006 e 20\%, a partir de 2007.

Nos anos seguintes, como destacam Moura e Henrique (2008), as instituições de EPT são impactadas pelos decretos 5.478/05 (BRASIL, 2005b) e 5.840/06 (BRASIL, 2006), que buscavam resolver a hierarquia das normas e inserir o público da EJA à rede federal seguindo uma proposta de integração curricular.

Com o objetivo de enfrentar as "descontinuidades e o voluntarismo que marcam a EJA no Brasil” (MOURA, 2006, p. 2) e de integrar a formação profissional à Educação Básica, contribuindo para a evolução socioeconômica de jovens e adultos, as instituições de EPT iniciam a implantação do PROEJA, Programa de Integração à Educação Básica na Modalidade Educação de Jovens e Adultos, apoiadas no decreto 5.840/2006 e no Documento Base do PROEJA (BRASIL, 2007). A baixa expectativa de inclusão de jovens e adultos de classes populares no sistema público de Educação Profissional e as experiências isoladas de algumas instituições de EPT nessa modalidade são algumas das justificativas trazidas por este documento para a implantação do programa.

Conforme o Parecer 11/2000 (BRASIL, 2002), a EJA como modalidade deve ser entendida, trabalhada e incorporada no sentido lato da palavra. De acordo com o documento:

O termo modalidade é diminutivo latino de modus (modo, maneira) e expressa uma medida dentro de uma forma própria de ser. Ela tem, assim, um perfil próprio, uma feição especial diante de um processo considerado como medida de referência. Trata-se, pois, de um modo de existir com característica própria (BRASIL, 2002, p. 26). (Grifo do autor).

O Documento Base (BRASIL, 2007) reafirma que estão inseridos na EJA jovens e adultos marginais ao sistema, sujeitos fora da faixa etária escolar dita como "regular", vindos do insucesso, de problemas de não permanência ou da exclusão do ensino regular, sendo eles trabalhadores formais ou informais, desempregados, pais e mães de família, jovens afastados da escola, sujeitos marcados por raça, cor, gênero, entre outros, frente a uma sociedade excludente.

O PROEJA, de acordo com Moura (2006), nasce frente a essa realidade, com uma proposta de agraciar o público da EJA inserindo o mesmo na rede federal de Educação, promovendo, assim, a elevação de escolaridade unida à profissiona- 
lização, no sentido de contribuir para a integração sociolaboral de forma gratuita, igualitária e universal. Com esta proposta, o autor ainda destaca o foco da formação: a "perspectiva precisa ser, portanto, de formação na vida e para vida e não apenas do mercado ou para ele." (MOURA, 2006, p. 8).

A formação integral assumida como característica marcante do PROEJA, ainda segundo Moura (2006), tem como finalidade a superação histórica presente na Educação brasileira entre teoria e prática; cultura geral versus cultura técnica. Tal dualidade torna-se mais acentuada ao deparar-se com as desigualdades e exclusões sociais. Assim, no Documento Base do PROEJA (BRASIL, 2007) torna-se evidente a necessidade de se ter uma formação norteada pela prática social vivenciada pelo estudante durante seu desenvolvimento e preparação para a vida, alicerçada na formação científica, humanística e tecnológica, permitindo-lhe o desenvolvimento efetivo dos fundamentos para a atividade política, social, cultural, econômica e no mundo do trabalho, visando à continuidade de estudos como meio e não como finalidade em sim mesma.

Além disso, na leitura do mesmo documento, percebe-se que este programa tem como princípios de consolidação de sua política os fundamentos da EJA, do Ensino Médio e dos cursos de formação profissional. Esses princípios são: a inclusão; a inserção orgânica da modalidade EJA integrada à Educação profissional nos sistemas públicos; a ampliação do direito à Educação Básica; o trabalho como princípio educativo, a ação transformadora no mundo, para si e para os outros; a pesquisa como fundamento da formação do sujeito envolvido, contribuindo para sua autonomia intelectual e as condições etárias, de gênero, de relações étnico raciais como base da formação humana e dos modos de produção das identidades sociais.

Nesse sentido, com a perspectiva de assegurar a formação humana, com acesso ao universo de saberes e conhecimentos científicos e tecnológicos integrados a uma formação profissional que permita compreender o mundo, compreender-se no mundo e nele atuar na busca da melhoria das próprias condições de vida e da construção de uma sociedade socialmente justa, o Instituto Federal de Educação, Ciência e Tecnologia do Sudeste de Minas, Campus Rio Pomba, organizou-se para que no ano de 2008 fosse oferecida a primeira turma de Curso Técnico em Agente Comunitário de Saúde (ACS) na modalidade PROEJA; porém, sem acontecer antes no campus uma discussão coletiva e/ou capacitação do corpo docente para atuar nesta modalidade de ensino.

\section{A atividade proposta}

Para atender às peculiaridades do Curso Técnico em ACS - PROEJA em relação à Matemática, propôs-se a elaboração de um material didático específico para o 
curso, o caderno temático "Saúde e números", do qual será apresentada a aplicação da sua unidade 9: "Conhecendo a realidade do $\mathrm{PSF}^{1}$ no Brasil", com a turma do $4^{\circ}$ período do curso durante o $1^{\circ}$ semestre de 2010. Para a coleta dos dados apresentados neste artigo foram utilizados como instrumentos: diário de bordo, gravador de voz, máquina fotográfica e máquina filmadora.

A unidade proposta tem como objetivo apresentar aos estudantes o plano cartesiano, possibilitar sua compreensão, a representação e localização de suas coordenadas, além de desenvolver o raciocínio combinatório por meio da resolução de problemas.

A escolha por trabalhar com essa unidade se deu após a pesquisa dos planos de cursos arquivados na coordenação geral de ensino do Campus Rio Pomba, onde verificou-se que a turma já possuía conhecimento de funções de primeiro e segundo graus, favorecendo a recordação do conteúdo de coordenadas cartesianas e a visão aplicada deste à atuação de um ACS por meio do material proposto. Além disso, segundo o programa analítico, o próximo conteúdo a ser ministrado seria Análise Combinatória, tópico abordado em três atividades da unidade proposta, permitindo ao professor introduzir o raciocínio combinatório e o princípio fundamental da contagem por meio deste material e, consequentemente, aprofundá-lo a partir da interação com os estudantes.

A atividade é iniciada com um texto jornalístico, onde são apresentados dados estatísticos sobre a realidade das equipes do PSF no Brasil, por meio dos quais os alunos são levados a calcular médias aritméticas e porcentagem na seção "Discutindo o texto". Nas "Atividades", os estudantes podem visualizar e investigar o mapa da cidade de Rio Pomba e sua divisão em três postos de atuação. A partir do mapa, portanto, são propostos três problemas relacionados à localização no plano cartesiano e três problemas de raciocínio combinatório. Na seção seguinte, promove-se um diálogo com outras áreas do conhecimento, permitindo uma reflexão sobre a atuação do ACS, a relação do número de agentes com o número de habitantes e o investimento financeiro nesta área.

Em "Dialogando com a Matemática", são apresentados os conceitos, nomenclaturas e características do plano cartesiano e de suas coordenadas. Finalizando a atividade, os estudantes são convidados a investigar o plano cartesiano por meio do software Geogebra, reproduzindo pontos, calculando distâncias, construindo polígonos e verificando regularidades.

\section{O desenvolvimento da aula}

Inicialmente o material foi distribuído individualmente aos estudantes e estes tiveram a liberdade para se organizarem em equipes ou não. Foi solicitado a um 
estudante que fizesse a leitura em voz alta da unidade, enquanto os demais alunos acompanharam. Nessa etapa foi observada grande dificuldade na leitura das quantidades apresentadas, em especial das representações decimais como, por exemplo, "5,3 mil municípios". Por meio da intervenção do professor, foi possível proporcionar aos alunos uma revisão dos conceitos de ordem, classe, números decimais e suas diferentes representações, a fim de sanar as dúvidas levantadas pelos alunos a respeito da representação decimal. Os estudantes ficaram surpresos com os valores trazidos pelo texto e com a ampliação constante das funções e aplicações das políticas de saúde familiar no Brasil.

Logo nas primeiras questões de cálculo, percebeu-se que os estudantes tiveram necessidade de resolver as simplificações ou cálculos complexos por meio de contas ou processos de proporção, como se pode verificar nas anotações abaixo (Figuras 1 e 2)

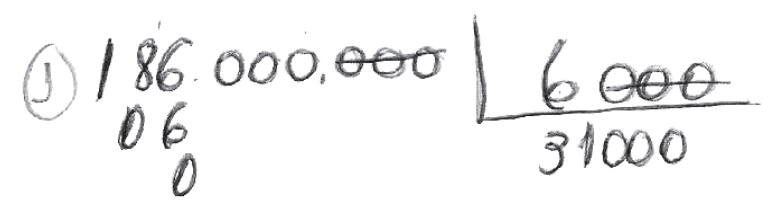

Figura 1: Resposta do aluno 7 à atividade

Fonte: Dados da pesquisa

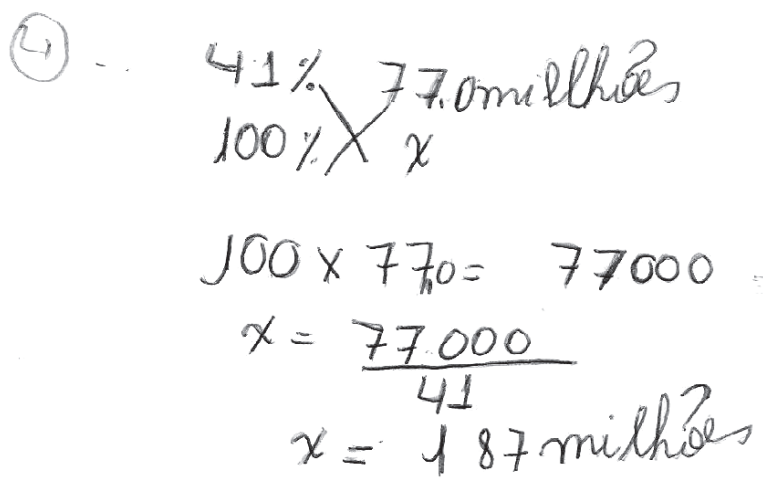

Figura 2: Resposta do aluno 7 à atividade

Fonte: Dados da pesquisa 
Assim, nota-se que os estudantes passam a se apropriar de novas estratégias de processos escolares matemáticos, mas sem abandonar as estratégias e experiências adquiridas anteriormente, conforme o diálogo abaixo:

Aluno 8: Ah... 186.000.000:6000... $18: 6=3$ e $6: 6=1$, então é 31 .

Professor: E os zeros?

Aluno 8: É só contar... 6 zeros, tira 3, sobra 3. Então 31 com três zeros... é 31.000 .

Ao transpor a primeira página da unidade estudada, a turma transformou-se ao visualizar o mapa da cidade local. Todos os alunos residentes em Rio Pomba procuravam a localização de seu trabalho, de sua residência, das proximidades e tentavam inserir ali as características locais que conheciam como praças, rodovias etc. Isso ocorreu, possivelmente, porque a situação apresentada na atividade trazia significado para os estudantes, possibilitando, assim, uma interação entre os mesmos e o material, conforme afirma Frankenstein apud Silva (2007)2: “o conteúdo de uma educação para a consciência crítica deve ser desenvolvida pela busca com os estudantes de ideias e experiências que dêem significado às suas vidas." (SILVA, 2007, p. 56).

Ainda nessa perspectiva, Cabral (2007) destaca a importância de se trazer problemas da realidade do aluno para o contexto escolar, para que não se corra o risco de trabalhar com falsos problemas e, assim, mais uma vez, aprisionar a Matemática à escola, afastando os jovens e adultos de sua aprendizagem e significação.

Para a interação dos estudantes provenientes de outras localidades, sugere-se que o professor solicite, como atividade extra-classe, o mapa de sua cidade para ser socializado junto à turma. Outra sugestão de atividade interdisciplinar é a representação, por meio de mapas ou maquetes, das cidades onde residem os estudantes e, consequentemente, as áreas de cobertura dos seus PSFs. Essa atividade pode ser desenvolvida por professores de várias outras disciplinas, como, por exemplo de Geografia, Artes, Saúde e Matemática.

As atividades relacionadas à localização dos postos de saúde no plano cartesiano foram realizadas com prontidão e interesse por parte dos alunos, porém, verificamos pouca atenção dos alunos à notação das coordenadas apresentadas logo no exercício número 1 , visto que quinze dos dezessete estudantes não registraram as

2 FRANKENSTEIN, M. Educação Matemática crítica: uma aplicação da epistemologia de Paulo Freire. In: BICUDO, Maria Aparecida. V. (Org). Educação Matemática. 2.ed. São Paulo: Centauro, 2005. p. 101-140. 
coordenadas utilizando os parênteses, conforme foram apresentadas outras coordenadas no enunciado do exercício, como se observa na figura 3, abaixo:

1) A agente comunitária Lúcia atende a área delimitada pelo polígono formado pelas coordenadas $(1, \mathrm{E}),(1, \mathrm{H}),(3, \mathrm{E}),(3, \mathrm{H})$. A qual posto ela pertence?

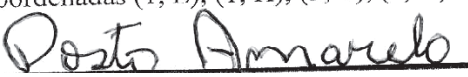

2) Carlos atende ao bairro São Manoel, referente ao Posto vermelho. Quais seriam as coordenadas do polígono que limita a sua área de atendimento? $4 F$ 4 E $3 F 3 E$

3) Júlio atende ao bairro Santa Helena, referente ao Posto verde. Quais seriam as coordenadas do polígono correspondente a sua área de atendimento?

$50,5 E, 6 D, 6 E$

Figura 3: Questões 1, 2 e 3 resolvidas pelo aluno 8

Fonte: Dados da pesquisa

Percebe-se que a notação acima não é a representação formal de coordenadas cartesianas, mas possibilita a localização e a sua compreensão por parte dos sujeitos. Este tipo de notação está presente em outras áreas do conhecimento como a Informática (planilhas) e Arquitetura (cad). A esse respeito, Fonseca (2007) destaca que as flexibilizações nas exigências de padronização na expressão dos procedimentos matemáticos são marcos sensíveis da Educação Matemática e da Educação de Jovens e Adultos. Além de que, seguindo as orientações dos Parâmetros Curriculares Nacionais (BRASIL, 1999), deve-se incentivar o aluno a expressar-se oral, escrita e graficamente em situações matemáticas e valorizar a precisão da linguagem matemática. Nesta perspectiva, a unidade retoma a notação formal das coordenadas cartesianas na seção "Investigando com a ajuda da tecnologia".

Conforme mencionado anteriormente, a unidade proposta estava adequada ao planejamento da série, possibilitando colocar os estudantes no contexto do pensamento combinatório e permitindo ao professor aprofundar o experimental matemático de acordo com o interesse dos alunos. Porém, ao iniciar as questões relacionadas ao princípio fundamental da contagem e o raciocínio combinatório, os estudantes tiveram dificuldades de compreensão do enunciado. De um total de dezessete alunos, doze tiveram dificuldade em resolver as atividades, entrando em conflito com as diversas respostas levantadas pelos colegas. Apesar disso, quando foram incentivados a registrar as possibilidades de duplas a serem formadas pelos agentes comunitários no problema número 6 , conseguiram raciocinar e registrar corretamente, conforme demonstrado a seguir nas figuras 4 e 5: 
6) No Posto Verde há 6 agentes de saúde para atenderem 3 bairros diferentes. De quantas formas diferentes podcmos organizar esses agentes em dupla?

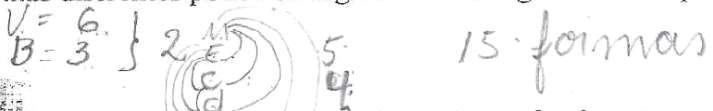

Dialogando com outrás áreas do conhecimento:

igura 4: Resposta do aluno 10 à questão proposta

Fonte: Dados da pesquisa
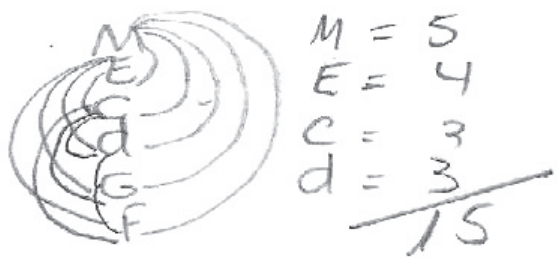

Figura 5: Resposta do aluno 9 à questão proposta

Fonte: Dados da pesquisa

Já na seção "Dialogando com outras áreas do conhecimento", os estudantes discutiram sobre a importância do ação do PSF e do investimento e trabalho contínuos na área de saúde familiar, onde se percebeu grande maturidade dos mesmos em relação ao campo de atuação e ao mundo do trabalho em que estão ou estarão inseridos. (Figuras 6 e 7):

Dialogando com outras áreas do conhecimento:

Qual foi o investimento médio da área de saúde, por pessoa, no ano de 2007?

$\pm 24,90$ pow pessoa

$>$ Qual é a melhor forma de fazer o atendimento: em dupla ou individualmente? Justifique. $D$ atendimento undirclual, pois a pamilia pode ter confianca em uma pessoa e näa ter na outra.

> Qual a frẹ̀üência de visitação dos agentes comunitários de saúde a sua casa? Apesar das visitas ter gue ser uma vey por més, ela

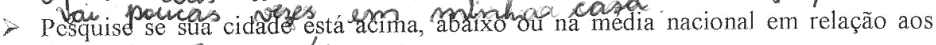
dados acima. \&on médea

Figura 6: Resposta do aluno 9 à atividade

Fonte: Dados da pesquisa 
Dialogando com outras áreas do conhecimento:

Qual foi o investimento médio da área de saúde, por pessoa, no ano de 2007 ? $R= \pm 24,90$ por pessoo

$>$ Qual é a melhor forma de fazer o atendimento: em dupla ou individualmente? fustifique $\theta$ alendernento tem que ser fetto undividialmente

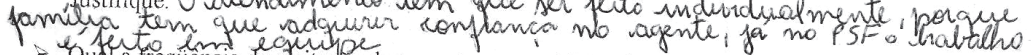

- Qual a requência de visitaçoo dos agentes comunitários de saúde a sua casa?

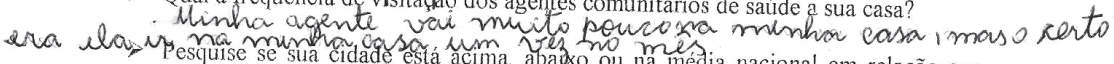

escelação aos

dados acina Esta na media

Figura 7: Resposta do aluno 10 à atividade

Fonte: Dados da pesquisa

Pode-se afirmar, portanto, diante do exposto, que atividades de caráter investigativo que requerem maior autonomia dos estudantes ainda são pouco utilizadas nas aulas de Matemática (PONTE, BROCARDO e OLIVEIRA, 2005), o que gera certa resistência, como verificamos no relato a seguir (Figura 8):

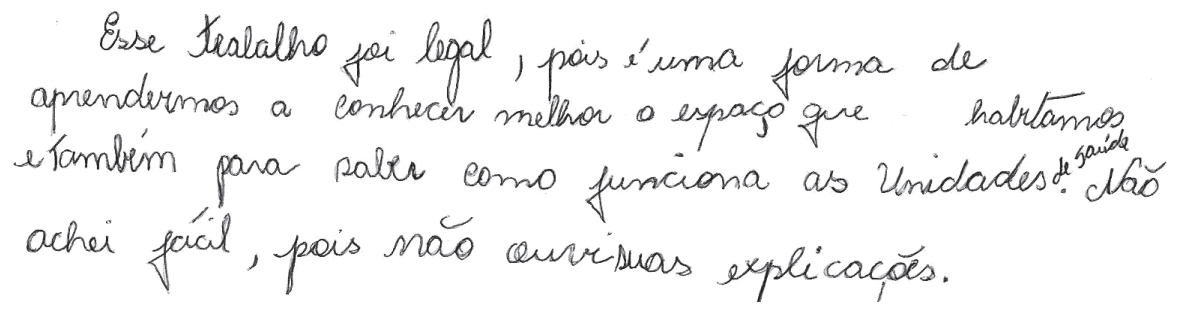

Figura8: Colocação realizada pelo aluno 11

Fonte: Dados da pesquisa

Assim, verifica-se que aulas expositivas, onde o papel do professor é repassar os conhecimentos e ao estudante cabe apenas a função de acompanhar as explicações, assimilar os conteúdos transmitidos e reproduzi-los nos exercícios propostos ainda está muito presente na sala de aula.

Nessa turma, a aplicação do material obteve certa resistência por parte de uma dupla de estudantes que tem como uma boa aula de Matemática aquela de caráter expositivo, com conceitos e modelos escritos na lousa, juntamente com uma lista 
de exercícios a serem feitos, conforme as orientações do professor, com o objetivo de preparar o aluno para o vestibular e os concursos do mercado de trabalho, como pode ser verificado na figura 9 , abaixo:

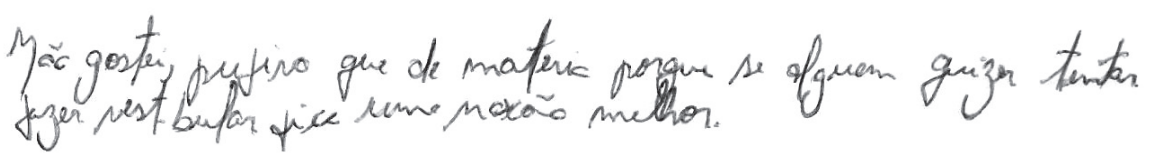

Figura 9: Colocação do aluno 12 à questão proposta

Fonte: Dados da pesquisa

O modelo de ensino-aprendizagem requerido por esses estudantes vai de encontro à proposta de formação do PROEJA citada por Moura (2006), quer seja, de uma formação na vida e para a vida e não apenas uma qualificação do mercado, como aponta o autor:

Em síntese, a oferta (dos cursos técnicos integrados) organizada se faz orientada a proporcionar a formação de cidadãos-profissionais capazes de compreender a realidade social, econômica, política, cultural e do mundo do trabalho, para nela inserir-se e atuar de forma ética e competente, técnica e politicamente, visando à transformação da sociedade em função dos interesses sociais e coletivos, especialmente os da classe trabalhadora. (MOURA, 2006, p. 12).

Para finalizar essa unidade, na semana seguinte, os estudantes foram levados ao laboratório de informática da coordenação acadêmica de Matemática, Física e Estatística (CAMFE) do campus, onde tiveram, à sua disposição, vinte e dois computadores com o software Geogebra instalado (Figuras 10 e 11). Para uma melhor interação dos estudantes com o programa, foi instalado, ainda, um data-show para a reprodução em imagem ampliada das ações executadas. 


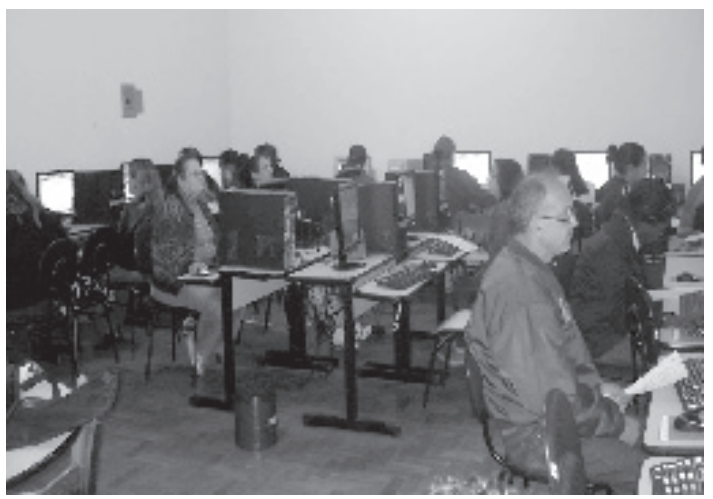

Figura 10: Visão do laboratório de informática durante a aplicação das atividades Fonte: Dados da pesquisa

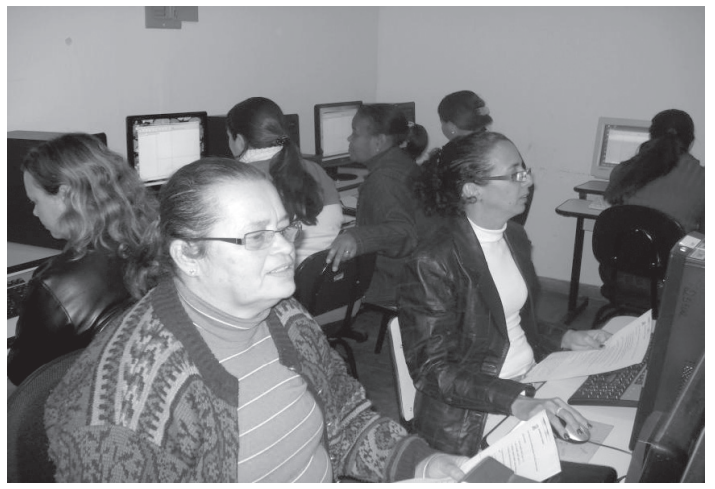

Figura 11: Estudantes utilizando a folha de atividades e o software Geogebra Fonte: Dados da pesquisa

Logo no início da aula no laboratório de informática, pôde-se verificar a falta de habilidade dos estudantes com o computador: quatro não souberam ligar o estabilizador, dois não sabiam lidar com o mouse, uma não sabia digitar letras maiúsculas e quatro não encontraram o botão que ligaria a CPU.

Porém, a curiosidade dos alunos diante dos comandos do Geogebra foi crescente. Os estudantes não desistiram frente às dificuldades, pelo contrário, começaram a dialogar com os colegas mais próximos, mostrando determinação, trabalho coletivo, fascínio pela atividade e auto-estima. É importante ressaltar que, à medida que os estudantes foram interagindo com o computador, as dificuldades foram sendo minimizadas. 
Antes mesmo, porém, de iniciar a atividade, uma estudante exclamou ao ver sua tela repleta de pontos: "Eu quero apagar... só vai aparecendo... Ai meu Deus do céu.... Aqui, Como eu faço para apagar... (riso). Eu fui clicando e foi aparecendo sem eu querer". (Aluna 5).

Frankenstein (2005) destaca, nesse sentido, que a ansiedade matemática das pessoas pode ser um obstáculo para a Educação Matemática Crítica. Portanto, a fim de reduzir a ansiedade causada pelo ambiente informatizado, foi sugerido que os estudantes fizessem a leitura das atividades em voz alta e que, juntos, fizessem sua resolução das atividades passo a passo.

Assim, logo na primeira atividade, os estudantes recordaram a notação de uma coordenada e a distância entre dois pontos. O que mais chamou a atenção dos mesmos foi o fato de poderem movimentar os pontos inicialmente inseridos no plano cartesiano e as consequências dessa movimentação, já que as coordenadas do ponto, o seguimento de reta formado e a distância eram modificados (Figuras 13 e 14).

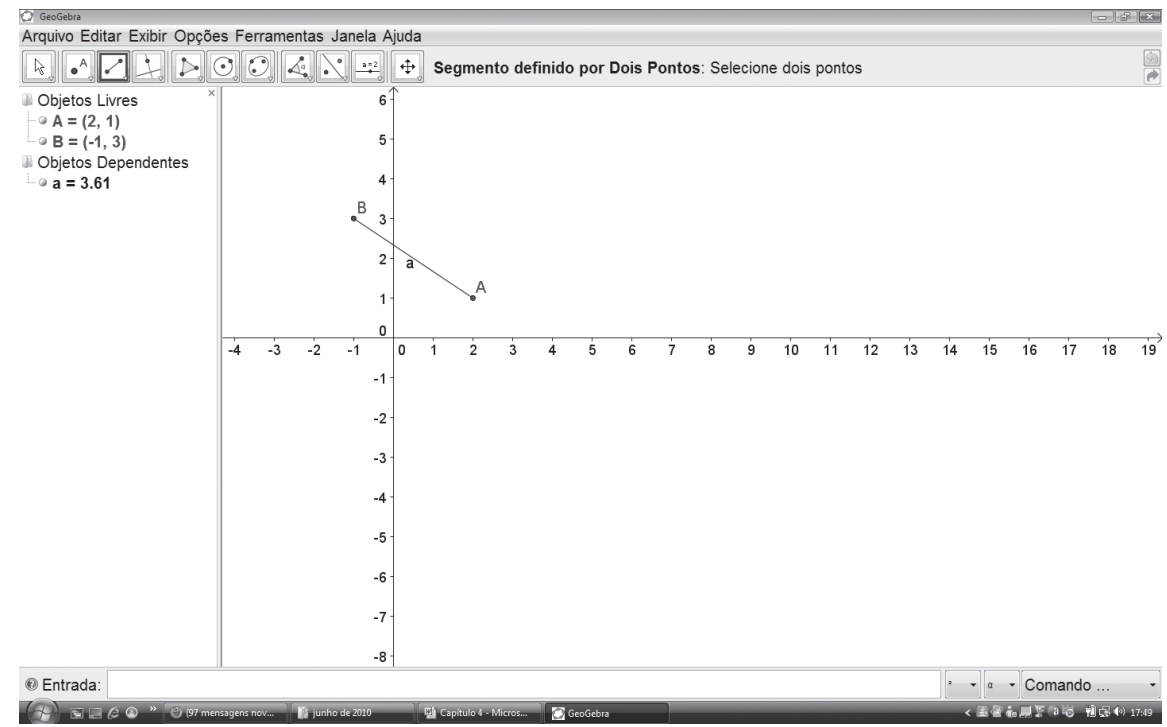

Figura 13: Atividade realizada pelo estudante 1 seguindo a indicação do enunciado Fonte: Dados da pesquisa 


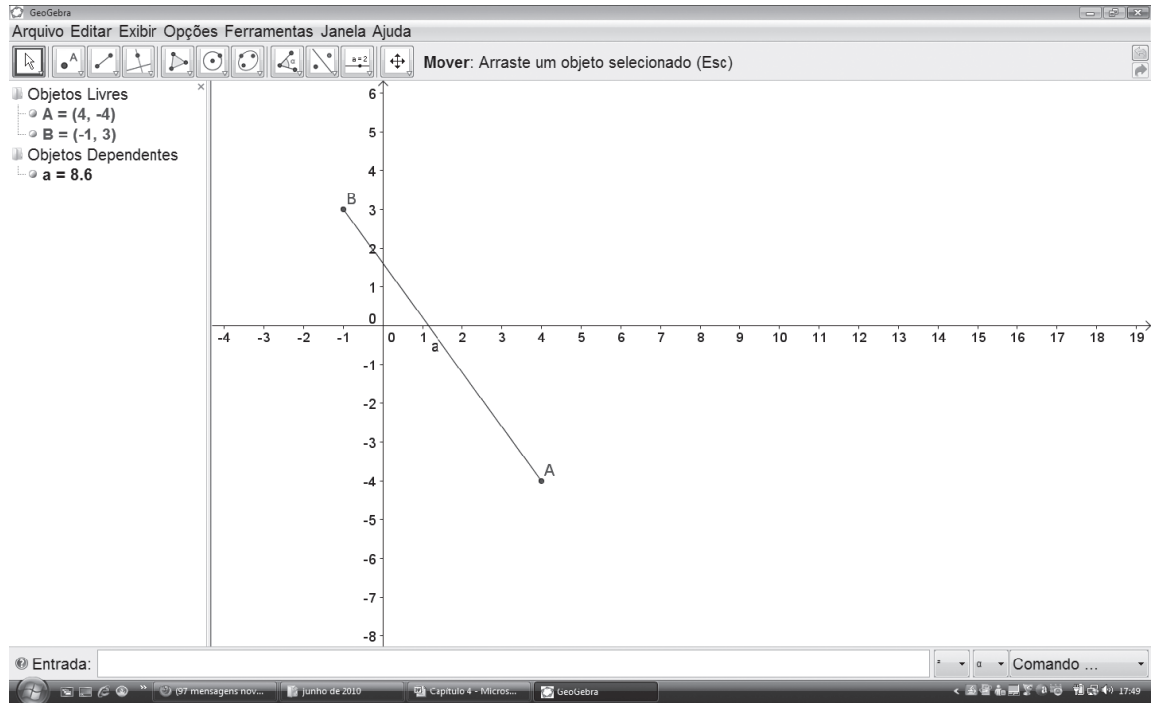

Figura 14: Atividade da imagem anterior após a movimentação do ponto $\mathrm{A}$ Fonte: Dados da pesquisa

$\mathrm{Na}$ atividade seguinte, cinco estudantes tiveram dificuldade em manusear o mouse e representar o triângulo, porém, naquele momento, já estavam mais adaptados com o ambiente informatizado. Percebe-se, com isso, que as tecnologias de informação e comunicação (TICs) devem ser incentivadas e utilizadas nas turmas de EJA, conforme indica o documento nacional preparatório à VI Conferência Internacional de Educação de Adultos (VI CONFITEA):

As TICs se espalham na prática irrecorrível, mudando a vida, as relações e as lógicas de apropriação do tempo e do espaço, agora submetidos a novos ordenamentos e apreensões. Convive-se com as antigas tecnologias, mas não se abre mão das novas em todos os campos da vida e cuida-se de evitar que novas exclusões sejam processadas. (BRASIL, 2009, p. 34).

$\mathrm{Na}$ atividade 8 , é solicitada a criação de um ponto $\mathrm{C}$, onde o aluno tem liberdade para escolher suas coordenadas. Por meio do diálogo abaixo, verificou-se que alguns estudantes não sabiam lidar com esta autonomia:

Aluno 6: Qual é o ponto?

Aluno 9: Não sei. 
Professor: Você pode criar as coordenadas.

Aluno 6: Vou copiar do dela. (indicando a atividade do aluno 7)

Professor: Não senhora.... O que forma uma coordenada?

Aluno 8: Dois números, $\mathrm{x}$ e $\mathrm{y}$.

Aluno 6: Então eu vou colocar 4 e 2. Vou colocar 4 vírgula 2...risos... você (olhando para o professor) não quer deixar eu colocar igual ao dela.

Nesse sentido, Freire (1996) enfatiza a importância da democracia e da liberdade na sala de aula, favorecendo a formação de um cidadão consciente e responsável, capaz de se reencontrar no aprendizado da autonomia. Segundo o autor:

O papel da autoridade democrática não é, transformando a existência humana num calendário escolar tradicional, marcar as lições de vida para as liberdades, mas, mesmo quando tem um conteúdo programático a propor, deixar claro, com seu testemunho, que o fundamental no aprendizado do conteúdo é a construção da responsabilidade da liberdade que se assume. (FREIRE, 1996, p. 58).

A esta altura da atividade, duas alunas já haviam saído da posição de participantes para serem colaboradoras da aplicação. Ao conseguirem seguir as atividades sem maiores dúvidas, passaram a auxiliar os colegas mais próximos e até repetir as explicações dadas pelo professor, como mostra o diálogo a seguir:

Aluna 10: Não... Vicentina... dois números... coordenada x e y. Abre parênteses, um número, vírgula, outro número.

Aluna 9: Da mesma maneira.

Aluna 10: Isso. Conseguiu?

Aluna 10: Olha o meu C onde é que está ...risos... olha o seu...risos...

Aluna 11: O meu tá diferente.

Aluna 9: Cada um será diferente, são pontos diferentes.

Vencidas as primeiras dificuldades, os estudantes iniciaram a construção de polígonos. Ao construírem o triângulo, os estudantes verificaram a diversidade de tamanhos, coordenadas e localizações nas telas dos computadores, fato que gerou curiosidade e levou quatro estudantes a movimentarem seus vértices a fim de obterem figuras diferentes das representadas inicialmente:

Professor: Agora vamos criar um polígono. Como vamos criar um polígono? Aluno 9: Vamos no comando! 
Aluno 7: Nossa... o meu está tão magrinho...(risos)... Eu posso modificar o tamanho dos lados?

Professor: Pode sim.

Aluno 7: Como?

Professor: Arrastando um vértice.

Aluno 6: Olha que legal!

A partir das falas acima, percebe-se que os estudantes interagiram com o software e com a atividade. Henriques (2000) ressalta que quando se pode trabalhar no papel usando lápis e borracha, geralmente a análise é centrada num objeto estático, e o aluno se limita àquele objeto sobre o papel, enquanto que nos ambientes computacionais, esta análise se torna mais abrangente, pois permite a manipulação direta em tempo real. O diálogo abaixo evidencia, mais uma vez, a interação e dinâmica permitidas pela atividade no Geogebra:

Professor: Para a gente concluir, o que seriam os objetos livres?

Alunos: $E$ os pontos: A, B, C, ...

Professor: Quem criou os pontos?

Alunos: Nós.

Professor: O que seriam os objetos dependentes?

Alunos: Os lados e as distâncias.

Professor: Por que eles são dependentes?

Alunos: Por que eles podem aumentar e diminuir.

Professor: De acordo com o quê?

Alunos: Com o mouse. Com os nossos movimentos. Com os pontos e as mudanças mudam quando a gente movimenta os pontos.

Ao final da atividade, o professor iniciou, oralmente, uma revisão das descobertas e conceitos abordados durante a aula, como mostra o diálogo:

Professor: O que podemos recordar dessa aula? As coordenadas são representadas por...

Alunos: Pontos.

Professor: Como são os pontos:

Alunos: Abre parênteses, uma coordenada, vírgula, outra coordenada, fecha parênteses.

Professor: Os pontos são representados por letras...

Alunos: Maiúsculas. 
Professor: Com três pontos eu posso formar...

Alunos: Um polígono.

Professor: Que polígono? Como ele chama?

Alunos: Um triângulo.

Professor: Se eu "mexer" num vértice de um polígono eu ...

Alunos: Modifico os lados.

Professor: E vice-versa.

Com o diálogo acima, é possível verificar a compreensão da notação matemática formal de coordenadas cartesianas, que fora iniciada na semana anterior, na seção "Atividade", além de noções de Geometria de forma mais concreta $\mathrm{Na}$ transcrição acima, portanto, percebe-se que a notação formal das coordenadas foi trabalhada na atividade com o Geogebra de maneira proveitosa, pois os estudantes assimilaram-na e foram capazes de descrevê-la oralmente no feedback realizado pelo professor no fechamento da aula. Amorim (2003) destaca, nesse sentido, que com a utilização de meios informatizados, há grande possibilidade de uma aprendizagem significativa, participante e motivadora da Geometria.

Assim, verificando a opinião dos estudantes sobre a atividade no laboratório de informática com o Geogebra, levantou-se oralmente a seguinte questão, obtendo as respostas imediatamente:

Professor: É legal mexer na geometria com o Geogebra?

Alunos: É. É legal.

Professor: Vocês gostaram?

Alunos: Sim.

Professor: De vez em quando nós vamos fazer uma aula diferente assim, ok?

Aluno 5: Pode (nos) trazer mais vezes.

Aluno 6: Pena que o curso está acabando.

Para a surpresa da pesquisadora, ao final da aula, ao desligar os computadores, foi verificado que todos conseguiram sair do programa e desligar o computador sem o auxílio do professor. Esse fato pode ser um indicador de que, indiferente da idade ou escolaridade, a inclusão digital está ao alcance de todos.

\section{Considerações finais}

A proposta de um caderno contextualizado, composto por textos de diferentes gêneros de linguagem, busca a aproximação dos jovens e adultos com a atualidade, 
o hábito da leitura e os conteúdos matemáticos presentes no seu cotidiano. Com esta possibilidade de aproximar os estudantes, a leitura e a Matemática, espera-se o desenvolvimento das habilidades matemáticas e a formação de cidadãos funcionalmente alfabetizados (FONSECA, 2004).

A aplicação das atividades mostrou uma potencialidade além das expectativas, pois apenas uma dupla não esteve favorável à proposta, isto porque, independentemente da modalidade, existe a preocupação com o vestibular, tornando necessária essa discussão nas salas de aula de PROEJA.

Espera-se que, com este trabalho e com a divulgação do Caderno Temático "Saúde e Números", os educadores dos diversos cursos técnicos na modalidade PROEJA possam usufruir desse material para a formação integral dos jovens e adultos de seus cursos. Consequentemente, almeja-se, ainda, que, num futuro não muito distante, os educadores do PROEJA construam interdisciplinarmente materiais específicos para cada curso, reconhecendo, assim, a necessidade da formação técnica, básica e social do profissional, fazendo das diferenças a possibilidade para a criação de uma nova proposta de ensino e de uma aprendizagem significativa para um cidadão crítico e transformador da sociedade.

\section{Referências}

AMORIM, Joni de Almeida. A Educação Matemática, a internet e a exclusão digital no Brasil. Educação Matemática em Revista, Ano 10, n.14, jun, p.58- 66, 2003.

BRASIL, Ministério da Educação e do Desporto. Secretaria de Educação Média e Tecnológica. Parâmetros Curriculares Nacionais: Ensino Médio. Brasília: MEC, 1999. Disponível em http://portal.mec.gov.br/seb/arquivos/pdf/ciencian.pdf Acesso em: 28 fev. 2009.

BRASIL. Ministério da Educação e do Desporto. Parecer CEB 11/2000. In: SOARES, Leôncio. Diretrizes Curriculares Nacionais: Educação de Jovens e Adultos. Rio de Janeiro: DP\&A, 2002.

BRASIL, Ministério da Educação e do Desporto. Secretaria de Educação Média e Tecnológica. Portaria 2.080/05. Brasília: 13 de junho de 2005a.

BRASIL, Ministério da Educação e do Desporto. Secretaria de Educação Média e Tecnológica. Decreto 5.478, de 24 de junho de 2005. Institui, no âmbito federal de educação tecnológica, o Programa de Integração da Educação Profissional 
ao Ensino Médio na Modalidade de Educação de Jovens e Adultos - PROEJA. Brasília: 24 de junho de 2005 b.

BRASIL, Ministério da Educação e do Desporto. Secretaria de Educação Média e Tecnológica. Decreto 5.840, de 23 de julho de 2006. Institui, no âmbito federal, o Programa de Integração da Educação Profissional com a Educação Básica na Modalidade de Educação de Jovens e Adultos - PROEJA. Brasília: 23 de julho de 2006 .

BRASIL, Ministério da Educação e do Desporto. Secretaria de Educação Média e Tecnológica. PROEJA: Programa Nacional de Integração da Educação Profissional com a Educação Básica na Modalidade da Educação de Jovens e Adultos. Educação Profissional Técnica de Nível Médio / Ensino Médio - Documento Base. Brasília: MEC/SETEC, 2007.

BRASIL, Ministério da Educação e do Desporto. Secretaria de Educação Continuada, Alfabetização e Diversidade. Documento Nacional Preparatório à VI CONFITEA Internacional de Educação de Jovens e Adultos (VI CONFITEA). Brasília: MEC; Goiânia: FUNAPE/UFG, 2009.

CABRAL, Viviane Ribeiro de Souza. A importância do diálogo na mobilização dos conhecimentos dos alunos da educação de jovens e adultos na perspectiva da educação matemática crítica. In: ARAÚJO, Jussara de Loiola (org). Educação Matemática Crítica: Reflexões e diálogos. Belo Horizonte: Argvmentvm, 2007. p.61-71.

FONSECA, Maria da Conceição F. R. (Org.) Letramento no Brasil: habilidades matemáticas. São Paulo: Global, 2004.

FONSECA, Maria Conceição F. R. Educação Matemática de Jovens e Adultos. 2.ed. Belo Horizonte: Autêntica, 2007.

FRANKENSTEIN, M. Educação Matemática crítica: uma aplicação da epistemologia de Paulo Freire. In: BICUDO, Maria Aparecida. V. (Org). Educação Matemática. 2.ed. São Paulo: Centauro, 2005. p. 101-140.

FREIRE, Paulo. Pedagogia da autonomia: saberes necessários à prática educativa. 31 ed. São Paulo: Paz e Terra, 1996. 
HENRIQUES, A. Papel e Lápis x CABRI-GEOMETRE II: o caso do teorema de superfícies lunares. Educação Matemática em Revista. Ano 7, n. 8, junho, 2000.

MOURA, Dante Henrique. Eja: formação técnica integrada ao Ensino Médio. Salto Para o Futuro/Boletim 16. TV Escola, 2006.

MOURA, Dante Henrique; HENRIQUE, Ana Lúcia Sarmento. História do PROEJA: entre desafios e possibilidades. In: SILVA, Amélia Cristina Reis; BARACHO, Maria das Graças (Org.) Formação de educadores para o PROEJA: Intervir para integrar. Natal: CEFET-RN Editora, 2008. p.17-33.

PONTE, João Pedro da; BROCARDO, Joana; OLIVEIRA, Hélia. Investigações matemáticas na sala de aula. Belo Horizonte: Autêntica, 2005.

SILVA, Diva Souza. Educação Matemática Crítica e a perspectiva dialógica de Paulo Freire: tecendo caminhos para a formação de professores. In: ARAÚJO, Jussara de Loiola (Org). Educação Matemática Crítica: reflexões e diálogos. Belo Horizonte: Argvmentvm, 2007. p.49-59.

Submetido em agosto de 2011 Aprovado em maio de 2012 